\title{
Direct Comparison of the Enzymatic Characteristics and Superoxide Production of the Four Aldehyde Oxidase Enzymes Present in Mouse ${ }^{\sqrt{\$}}$
}

\author{
Gökhan Kücükgöze, Mineko Terao, Enrico Garattini, and Silke Leimkühler \\ Institut für Biochemie and Biologie, Universität Potsdam, Potsdam, Germany (G.K., S.L.); Laboratory of Molecular Biology, \\ Department of Biochemistry and Molecular Pharmacology, Istituto di Ricerche Farmacologiche Mario Negri, Milano, Italy \\ (M.T., E.G.)
}

Received March 13, 2017; accepted May 15, 2017

\section{ABSTRACT}

Aldehyde oxidases (AOXs) are molybdoflavoenzymes with an important role in the metabolism and detoxification of heterocyclic compounds and aliphatic as well as aromatic aldehydes. The enzymes use oxygen as the terminal electron acceptor and produce reduced oxygen species during turnover. Four different enzymes, mAOX1, mAOX3, mAOX4, and mAOX2, which are the products of distinct genes, are present in the mouse. A direct and simultaneous comparison of the enzymatic properties and characteristics of the four enzymes has never been performed. In this report, the four catalytically active mAOX enzymes were purified after heterologous expression in Escherichia coli. The kinetic parameters of the four mouse AOX enzymes were determined and compared with the use of six predicted substrates of physiologic and toxicological interest, i.e., retinaldehyde, $N^{1}$-methylnicotinamide, pyridoxal, vanillin, 4-(dimethylamino)cinnamaldehyde (p-DMAC), and salicylaldehyde. While retinaldehyde, vanillin, $p$-DMAC, and salycilaldehyde are efficient substrates for the four mouse AOX enzymes, $N^{1}$-methylnicotinamide is not a substrate of mAOX1 or mAOX4, and pyridoxal is not metabolized by any of the purified enzymes. Overall, mAOX1, mAOX2, mAOX3, and MAOX4 are characterized by significantly different $K_{M}$ and $k_{\text {cat }}$ values for the active substrates. The four mouse AOXs are also characterized by quantitative differences in their ability to produce superoxide radicals. With respect to this last point, $\mathrm{mAOX} 2$ is the enzyme generating the largest rate of superoxide radicals of around $40 \%$ in relation to moles of substrate converted, and $\mathrm{mAOX1}$, the homolog to the human enzyme, produces a rate of approximately $30 \%$ of superoxide radicals with the same substrate.
Aldehyde oxidases (AOX; EC 1.2.3.1) are molybdoflavoenzymes present in the cytosol of various animal species and tissues (Garattini et al., 2008). The number of active Aox genes varies according to the animal species considered. Although a single AOX protein is known in humans, at least four AOX enzymes (AOX1, AOX3, AOX4, and AOX2; Fig. 1) encoded by distinct genes have been described for the mouse and other rodents including rats (Garattini et al., 2009). The four mouse Aox genes cluster on chromosome 1 at a short distance from one another (Fig. 1). The human genome is characterized by an active gene homologous to mouse Aoxl and two inactive pseudogenes (Garattini et al., 2008).

The biochemical and physiologic functions of mammalian AOXs are still unclear (Garattini et al., 2008). Nevertheless, human AOX1 is an enzyme of emerging relevance for phase I drug metabolism (Garattini and Terao, 2012; Kitamura and Sugihara, 2014). Indeed, the number of xenobiotics acting as human AOX1 substrates is increasing. In particular, the current trend in drug development, focusing on the design and synthesis of molecules that are not recognized and inactivated by cytochrome P-450-dependent mono-oxygenases, has resulted in an enrichment of molecules that can be oxidized by AOXs (Pryde et al.,

This work was supported by the Deutsche Forschungsgemeinschaft [LE1171/ 8-1] and a fellowship from the University of Potsdam.

https://doi.org.org/10.1124/dmd.117.075937.

S This article has supplemental material available at dmd.aspetjournals.org.
2010; Garattini and Terao, 2012). Very little is known about the physiologic substrates of human AOX1 and other mammalian AOXs. AOXs are deemed to be involved in the oxidation of all-trans-retinal into all-trans-retinoic acid, the active metabolite of vitamin $\mathrm{A}$, and are believed to participate in vitamin B6 (pyridoxal) metabolism (Stanulović and Chaykin, 1971; Terao et al., 2009).

Whereas the expression of human AOX1 is relatively ubiquitous, the four mouse AOX enzymes are expressed in a tissue-specific manner (Garattini et al., 2003). The two enzymes mAOX1 and mAOX3 have largely overlapping expression profiles, and the highest levels of the two proteins are observed in liver, lung, and testis (Vila et al., 2004). Significant amounts of mAOX4 are detectable in the skin, the epithelium lining the oral cavity, the esophagus, and the Harderian gland, the major exocrine gland of the orbital cavity in many vertebrates. Knockout of the gene coding for mAOX4 causes perturbations in the circadian rhythm and resistance to diet-induced obesity (Terao et al., 2016). The expression of mAOX2 is restricted to the nasal cavity. High levels of the corresponding transcript and protein are detectable especially in Bowman's gland and olfactory mucosa (Terao et al., 2000). It has been suggested that the different mouse aldehyde oxidase enzymes have different substrate specificities. So far, mAOX3 is the only mouse AOX for which a crystal structure is available (PDB ID: 3ZYV) (Coelho et al., 2012), and the crystal structure of human AOX1 has recently been solved (Coelho et al., 2015). The structures were very similar in respect to their active sites, which suggested an overlapping spectrum of

ABBREVIATIONS: AOX, aldehyde oxidase; DCPIP, 2,6 dichlorophenolindophenol; FAD, flavin adenine dinucleotide; Moco, molybdopterin cofactor; Ni-NTA, nickel-nitrilotriacetic acid; $p$-DMAC, 4-(dimethylamino)cinnamaldehyde; XO, xanthine oxidase. 
substrates. Comparisons between the crystal structures of hAOX1 and mAOX3 demonstrated differences between the two enzymes in the position of one loop at the FAD site, the site of oxygen reduction. The loop close to the FAD pocket $\left(\mathrm{T}_{1230} \mathrm{RGPDQ}_{1235}\right)$ of $\mathrm{hAOX} 1$ is flipped by almost $180^{\circ}$ relative to the $\mathrm{mAOX} 3$ counterpart.

AOXs are cytosolic proteins and use molecular oxygen as the sole electron acceptor. During substrate oxidation and molecular oxygen reduction, AOXs generate significant amounts of $\mathrm{H}_{2} \mathrm{O}_{2}$ in addition to toxic $\mathrm{O}_{2}^{-}$radicals. This specific aspect of AOX activity has been largely overlooked and may be of pathophysiologic interest. In fact, significant levels of AOX activity are present in different tissues and AOXdependent $\mathrm{O}_{2}^{-}$production may contribute to damage by reactive oxygen species in vivo. Given these reasons and their potential relevance for the human enzyme, it is of interest to evaluate whether there are differences in the generation of $\mathrm{O}_{2}^{-}$among the four mouse AOX enzymes.

In this study, we set up and optimized an efficient system for the heterologous expression of the four mouse AOX enzymes in Escherichia coli. We used this system to purify significant amounts of highly purified and active $\operatorname{mAOX} 1, \operatorname{mAOX} 3, \operatorname{mAOX} 4$, and mAOX2. We compared the kinetic and spectroscopic properties of the four enzymes using a selected number of potential substrates. In addition, we determined the levels of superoxide anions generated by each enzyme. Our data reveal significant differences in the enzymatic characteristics and substrate specificities of the mouse AOX enzymes. This is of relevance for the use of mouse as an animal model in the context of drug discovery programs. The results presented support the idea that mice and other rodents are unlikely to represent suitable models for drug metabolism predictions in humans.

\section{Materials and Methods}

Cloning. The expression vector for mAOX4 was constructed using primers that allowed cloning into the NdeI and SalI restriction sites of the bacterial expression vector $\mathrm{pTrcHis}$ after polymerase chain reaction amplification of the full length mAox 4 cDNA obtained from the Harderian gland of C57BL/6N mice. The resulting plasmid was designated pMAOX4 and expresses the mAOX4 protein with an $\mathrm{N}$-terminal $\mathrm{His}_{6}$-tag. For the expression of $\mathrm{mAOX} 3$, we used the plasmid pMMA1 (Mahro et al., 2011). Codon-optimized genes for mAOX1 and mAOX2 were synthesized (GeneArt; Thermo Fisher Scientific, Sunnyvale, CA). They contain the DNA sequences of each gene with codons preferred by $E$. coli but do not result in a change of the amino acid sequence of the synthesized proteins. The mAox 1 and mAox 2 synthetic genes were cloned into the NdeI and SalI restriction sites of the pTrcHis expression vector and the resulting constructs were designated pMAOX1co and pMAOX2co.

Expression and Purification. For the heterologous expression of mAOX enzymes in E. coli, pMAOX4, pMAOX1co, and pMAOX2co were transformed into TP1000 ( $\triangle m o b A B)$ cells (Palmer et al., 1996). Cultures were grown at $30^{\circ} \mathrm{C}$ and $130 \mathrm{rpm}$, using 2-liter flasks containing 1 liter of Luria broth-peptone supplemented with $150 \mu \mathrm{g} / \mathrm{ml}$ ampicillin, $1 \mathrm{mM} \mathrm{Na}_{2} \mathrm{MoO}_{4}$, and $20 \mathrm{mM}$ isopropyl $\beta$-D-thiogalactoside. Cells were harvested after 24 hours of growth by centrifugation at $5000 \mathrm{~g}$ for 5 minutes and suspended in $50 \mathrm{mM}$ sodium phosphate buffer, $\mathrm{pH} 8.0$, containing $300 \mathrm{mM} \mathrm{NaCl}$. Two cycles of cell lysis were performed at $12^{\circ} \mathrm{C}$ and $135,000 \mathrm{kPa}$ (TS Benchtop Series Constant Systems, Northampton, UK). After the first cycle, cell lysates were treated with $1 \mathrm{mg} / \mathrm{ml}$ DNase I for 5 minutes. At the end of the process, cell lysates were cleared by centrifugation at $18,000 \mathrm{~g}$ for 1 hour at $4^{\circ} \mathrm{C}$. The supernatants were loaded onto nickelnitrilotriacetic acid (Ni-NTA) (QIAGEN, Valencia, CA) columns using $0.3 \mathrm{ml}$ of resin per liter of culture. The matrix was washed with 20 column volumes of the following two buffers consecutively: 1) $50 \mathrm{mM}$ sodium phosphate, pH.8.0, $300 \mathrm{mM} \mathrm{NaCl}$, and $10 \mathrm{mM}$ imidazole; 2) $50 \mathrm{mM}$ sodium phosphate, pH.8.0, $300 \mathrm{mM} \mathrm{NaCl}$, and $20 \mathrm{mM}$ imidazole. Proteins were eluted with $50 \mathrm{mM}$ sodium phosphate, pH.8.0, $300 \mathrm{mM} \mathrm{NaCl}$, and $250 \mathrm{mM}$ imidazole. For the further purification steps, the elution buffer was exchanged to $50 \mathrm{mM}$ Tris- $\mathrm{HCl}, 200 \mathrm{mM}$ $\mathrm{NaCl}$, and 1 mM EDTA (pH 8.0) with the use of PD-10 columns (GE Healthcare, Chalfont St. Giles, Buckinghamshire, UK). The purified enzymes were concentrated by ultrafiltration (Amicon 50-kDa MW cut-off; EMD Millipore Corporation, Billerica, MA). This was followed by size-exclusion chromatography on Superdex 200 columns (GE Healthcare) equilibrated in $50 \mathrm{mM}$ Tris- $\mathrm{HCl}$, $200 \mathrm{mM} \mathrm{NaCl}$, and $1 \mathrm{mM}$ EDTA (pH 8.0). Each fraction was analyzed by SDS-PAGE and only the fractions containing dimeric AOX proteins were combined. Purified proteins were stored at $-80^{\circ} \mathrm{C}$ until further use.

Chemical In Vitro Sulfuration. Purified enzymes were subjected to an in vitro chemical sulfuration step using a slight modification of a previously described protocol (Wahl and Rajagopalan, 1982). Proteins dissolved in buffer (50 mM Tris- $\mathrm{HCl}$, pH 8.0, containing $200 \mathrm{mM} \mathrm{NaCl}$ and $1 \mathrm{mM}$ EDTA) were incubated in an anaerobic chamber (Coy Laboratory Products, Grass Lake, MI) with sodium sulfide $(2 \mathrm{mM})$ as the sulfur source and sodium dithionite $(1 \mathrm{mM})$ to facilitate reduction. Methyl viologen $(25 \mu \mathrm{M})$ was used as an anaerobic indicator of the reaction. After a 1.5 -hour incubation at $4{ }^{\circ} \mathrm{C}$, reactions were stopped and the enzyme was equilibrated in $50 \mathrm{mM}$ Tris- $\mathrm{HCl}, 200 \mathrm{mM} \mathrm{NaCl}$, and $1 \mathrm{mM}$ EDTA (pH 8.0) using a PD-10 column.

Polyacrylamide Gel Electrophoresis. SDS-PAGE was performed with $10 \%$ gels under reducing conditions ( $\beta$-mercaptoethanol) using a standard protocol (Laemmli, 1970). Gels were stained with Coomassie Brilliant Blue R (SigmaAldrich, Munich, Germany). The molecular weight of the separated proteins was determined by comparison with a protein standard (molecular weight marker, MWM; Fermentas/Thermo Fisher Scientific).

Native-PAGE was performed with $7 \%$ gels under nonreducing and nondenaturing conditions. Samples were separated at a constant voltage of $40 \mathrm{~V}$. Gels were stained with Coomassie Brilliant Blue R. The in-gel enzymatic activity was visualized by staining with $500 \mu \mathrm{M}$ substrate (phthalazine or pyridoxal-5monophosphate) and $1 \mathrm{mM}$ Nitro blue tetrazolium chloride in $50 \mathrm{mM}$ Tris buffer.

UV-Visible Spectroscopy Absorption Spectroscopy. UV-visible absorption spectra of enzymes were recorded in 500- $\mu$ l quartz cuvettes using a Shimadzu UV-2600 spectrophotometer (Somerset, NJ). The specific molar extinction coefficient of $21,000 \mathrm{M}^{-1} \mathrm{~cm}^{-1}$ at $450 \mathrm{~nm}$ was used to determine the concentration of proteins. NADH reduction was achieved by the addition of $1 \mathrm{mM} \mathrm{NADH}$. Spectra were recorded under anaerobic conditions to avoid the reoxidation of enzymes by oxygen.

Steady-State Kinetics. Steady state kinetics of the purified enzymes were measured in $800 \mu \mathrm{l}$ of $50 \mathrm{mM}$ Tris- $\mathrm{HCl}$ buffer ( $\mathrm{pH} 8.0$ ) containing $1 \mathrm{mM}$ EDTA at $37^{\circ} \mathrm{C}$. The substrates pyridoxal 5-phosphate (converted to pyridoxic acid), $N^{1}$-methylnicotinamide [converted to 2-pyridone and 4-pyridone (Stanulović and Chaykin, 1971)], salicylaldehyde (converted to salicylic acid), 4-(dimethylamino)cinnamaldehyde ( $p$-DMAC) (converted to 4-(dimethylamino)cinnamic acid), vanillin (converted to vanillic acid), and retinaldehyde (converted to retinoic acid), were used in a concentration range around the $K_{M}$ of each substrate (the substrate and product of each reaction are shown in the Supplemental Figure S1). 2,6 Dichlorophenolindophenol (DCPIP) at a concentration of $100 \mu \mathrm{M}$ was used as the electron acceptor, which was converted to the colorless DCPIPH $\mathrm{H}_{2}$ leuco-form in a two-electron reduction step. The total enzyme concentration varied between 0.05 and $0.2 \mu \mathrm{M}$, depending on the AOX enzyme used. Enzyme activity was monitored at $600 \mathrm{~nm}$ with a computer-assisted spectrophotometer (Shimadzu UV-2600) coupled to a temperature-controlled cell holder (Shimadzu TCC-240A). Enzymatic activities were converted to turnover number $\left(k_{\text {cat }}\right)$ using the molar extinction coefficient of $16,100 \mathrm{M}^{-1} \mathrm{~cm}^{-1}$ for oxidized DCPIP. Three individual measurements were performed for each substrate concentration. Kinetic parameters were obtained by nonlinear fitting of the Michaelis-Menten equation. All fitting analyses were performed with the OriginPro $8.1 \mathrm{G}$ software (OriginLab, Northampton, MA).

Superoxide Production. The amount of superoxide produced during the enzymatic reactions was measured by monitoring the reduction of cytochrome $c$ (Sigma-Aldrich) at $550 \mathrm{~nm}$ and $37^{\circ} \mathrm{C}$. Reaction mixtures $(800 \mu \mathrm{l})$ contained $100 \mu \mathrm{M}$ cytochrome $c$ and $50 \mu \mathrm{M}$ substrate in $50 \mathrm{mM}$ Tris-HCl buffer ( $\mathrm{pH} 8.0$ ), $1 \mathrm{mM}$ EDTA. The enzyme concentrations varied between 0.05 and $0.1 \mu \mathrm{M}$ depending on the substrates ( $p$-DMAC or vanillin) used. Enzymes were added to the mixture to initiate the reaction and the absorbance change per minute was recorded with a spectrophotometer (Shimadzu UV-2600). Superoxide formation was calculated using an extinction coefficient of $21,000 \mathrm{M}^{-1} \mathrm{~cm}^{-1}$ for cytochrome $c$. AOX activity with $p$-DMAC and vanillin was determined by following the direct reduction of substrates at 398 and $347 \mathrm{~nm}$, respectively, in the presence of oxygen. The extinction coefficients of $30,500 \mathrm{M}^{-1} \mathrm{~cm}^{-1}$ (p-DMAC) and 


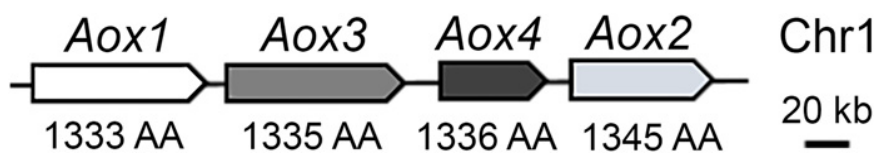

Fig. 1. Schematic representation of the chromosome 1 gene cluster coding for the four mouse AOX enzymes, showing the relative length and position of the four genes encoding the indicated AOX enzymes. The four genes are transcribed in the same direction, as indicated. The numbers below each gene indicate the number of amino acids for each encoded protein.

$25,100 \mathrm{M}^{-1} \mathrm{~cm}^{-1}$ (vanillin) were used to convert the absorbance changes to units of enzyme activity.

Quantification of Molybdenum and Iron. The molybdenum and iron contents of the purified AOX enzymes were determined by inductively coupled plasma optical emission spectrometry (ICP-OES) with an Optima 2100 DV (PerkinElmer Life and Analytical Sciences, Waltham, MA). Five-hundred microliters of protein samples at a final concentration of 5-10 $\mu \mathrm{M}$ were wetashed in an equal volume of $65 \%$ nitric acid by incubation at $100^{\circ} \mathrm{C}$ overnight. The samples were diluted with $4 \mathrm{ml}$ of distilled water. A multielement standard solution with known accuracy (standard solution XVI; Merck Millipore, Darmstadt, Germany) was used for the calibration. Measurements were performed in triplicate for all samples.

\section{Results}

Purification of the mAOX Enzymes from $\boldsymbol{E}$. coli. To compare the spectroscopic and kinetic properties of $\mathrm{mAOX} 1, \mathrm{mAOX} 3, \mathrm{mAOX} 4$, and $\mathrm{mAOX} 2$, we expressed the four mouse enzymes in a heterologous expression system in E. coli. Efficient expression of the recombinant mAOX3 protein in $E$. coli cells has been described previously (Schumann et al., 2009; Mahro et al., 2011) and has resulted in a calculated yield of $0.8 \mathrm{mg} / \mathrm{l}$ (Table 1). Under the same expression conditions, the yield of the $\mathrm{mAOX} 1$ protein from the corresponding native cDNA was relatively poor (Schumann et al., 2009). To overcome this problem, we generated an expression construct on the basis of an E. coli codon-optimized mAoxl gene that resulted in a 150-fold increase in average yield of mAOX1 (Table 1). In contrast to the previously described purification protocols, both mAOX1 and mAOX3 were purified by a simplified two-step purification method using Ni-NTA and size-exclusion chromatography. This resulted in increased yields of proteins characterized by an equal level of purity.

In contrast, the expression systems for mAOX 2 and $\mathrm{mAOX} 4$ were not established before. The construct used for the expression of mAOX4 in $E$. coli TP1000 contained the original cDNA amplified from the Harderian gland of C57BL/6N mice. For the expression of mAOX2, we generated an E. coli codon-optimized construct analogous to the one described for mAOX1. As detailed in the case of mAOX1 and mAOX3, the $\mathrm{mAOX} 2$ and $\mathrm{mAOX} 4$ proteins were purified from 12 liters of $E$. coli TP1000 cells. As with mAOX1 and mAOX3, the mAOX4 and mAOX2 enzymes were purified by the two-step purification procedure involving Ni-NTA and size-exclusion chromatography. Upon size-exclusion chromatography, mAOX1, mAOX2, mAOX3, and mAOX4 eluted as a single major peak, which corresponded to the catalytically active dimeric forms of each enzyme, with a molecular mass of $300 \mathrm{kDa}$ (Fig. 2). Monomers were also detectable for all AOX enzymes as minor peaks with an elution volume around $12.5 \mathrm{ml}$. In the case of AOX4, a substantial amount of protein showed a tendency to aggregate; however, the aggregates were well separated from the main dimeric peak upon size-exclusion chromatography (Fig. 2). The total yield of mAOX4 with an average of $1.1 \pm 0.4 \mathrm{mg}$ protein per liter of $E$. coli culture was slightly higher than that of $\mathrm{mAOX} 2$, resulting in $0.8 \pm 0.2 \mathrm{mg}$ protein per liter of E. coli culture (Table 1).

Relative to other molybdoenzymes, AOXs are characterized by the presence of a terminal sulfido ligand in the equatorial position of molybdopterin cofactor (Moco). This sulfido ligand is essential for the catalytic activity of both types of enzymes and it is inserted by a specific Moco sulfurase (Anantharaman and Aravind, 2002; Mendel and Leimkühler, 2015; Terao et al., 2016). As the E. coli and eukaryotic Moco sulfurases are substantially distinct from each other, expression of mammalian AOXs in E. coli generally results in a low saturation level of the terminal $\mathrm{Mo}=\mathrm{S}$ group (Mahro et al., 2011; Foti et al., 2016). However, after purification, the sulfido ligand can be ligated to the Moco of these enzymes by using a chemical sulfuration procedure (Wahl and Rajagopalan, 1982). Consistent with the above considerations, expression of the mAOX3 and mAOX4 in E. coli resulted in the isolation of two proteins with a low catalytic activity, which could be increased more than 10-fold following the chemical sulfuration step (Table 1). In the case of the two codon-optimized constructs used for mAOX1 and $\mathrm{mAOX} 2$ expression in E. coli, they resulted in the production of two catalytically inactive proteins (Table 1). However, mAOX1 and mAOX2 regained significant activity upon chemical sulfuration.

The UV-visible spectra of mAOX1, mAOX3, mAOX4, and mAOX2 displayed the characteristic features of molybdoflavoenzymes, showing an absorption maximum at $450 \mathrm{~nm}$ and a shoulder at $550 \mathrm{~nm}$ (Fig. 2, A-D insets). The ratios 5.0 for A280/A465 and 3.0 for A465/A550 are characteristics for metalloflavoproteins, including xanthine oxidase (XO) and AOX. A ratio of 3.0 for A465/A550 corresponds to an FAD to iron ratio of 1:4, whereas the ratio of 5.0 for A280/A465 is indicative of a high purity of the enzyme. Generally, the 280/450-nm absorption ratios of mAOX1, mAOX4, and mAOX2 were 5.7, 5.4, and 5.0, respectively (Table 1), which is consistent with a high level of enzyme purity. The similar 450/550 ratios determined for the enzymes are in line with the FAD and $[2 \mathrm{Fe}-2 \mathrm{~S}]$ saturation levels (Table 1).

SDS-PAGE was performed with the purified enzymes under reducing conditions with $\beta$-mercaptoethanol and showed the presence of one major $150-\mathrm{kDa}$ band in the case of $\mathrm{mAOX} 1$ and mAOX3. Under the

TABLE 1

General characterization of mAOX1, mAOX3, mAOX4, and mAOX2 after expression in E. coli TP1000 cells

\begin{tabular}{|c|c|c|c|c|c|}
\hline \multirow{2}{*}{ Sample } & \multicolumn{2}{|c|}{ Specific Activity $^{a}$} & \multirow{2}{*}{ Yield } & \multirow{2}{*}{ Ratio $(280 / 450)$} & \multirow{2}{*}{ Ratio (450/550) } \\
\hline & As Purified & After Chemical Sulfuration & & & \\
\hline & nmol $\min ^{-1} \mathrm{mg}^{-1}$ & nmol $\min ^{-1} \mathrm{mg}^{-1}$ & $m g / l$ of $\mathrm{E}$. coli Culture & & \\
\hline mAOX1 & N.D. & $146.7 \pm 19.5$ & $1.2 \pm 0.2$ & 5.7 & 3.2 \\
\hline $\operatorname{mAOX} 3^{b}$ & $104^{b}$ & $158^{b}$ & $0.8^{b}$ & $5.2^{b}$ & $3.1^{b}$ \\
\hline mAOX4 & $48.4 \pm 8.1$ & $585.2 \pm 37.3$ & $1.1 \pm 0.4$ & 5.4 & 3.1 \\
\hline $\mathrm{mAOX} 2$ & N.D. & $880.4 \pm 27.7$ & $0.8 \pm 0.2$ & 5.0 & 3.2 \\
\hline
\end{tabular}

N.D., no activity was detectable.

${ }^{a}$ Specific activity was measured using $50 \mu \mathrm{M}$ salicylaldehyde as substrate and $100 \mu \mathrm{M}$ DCPIP as electron acceptor.

${ }^{b}$ Data published by Mahro et al. (2011) with benzaldehyde as substrate. 
A

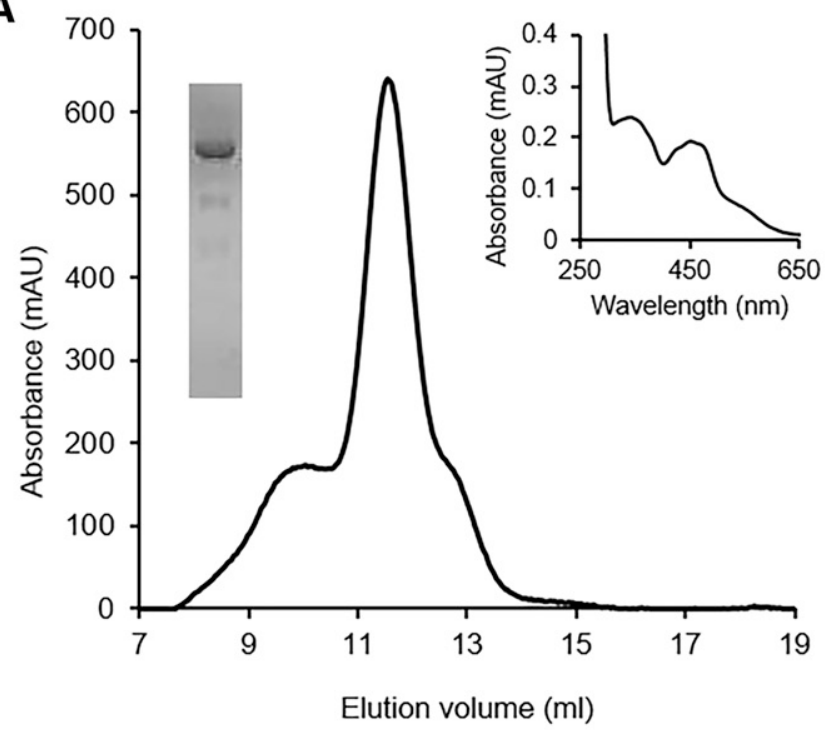

C

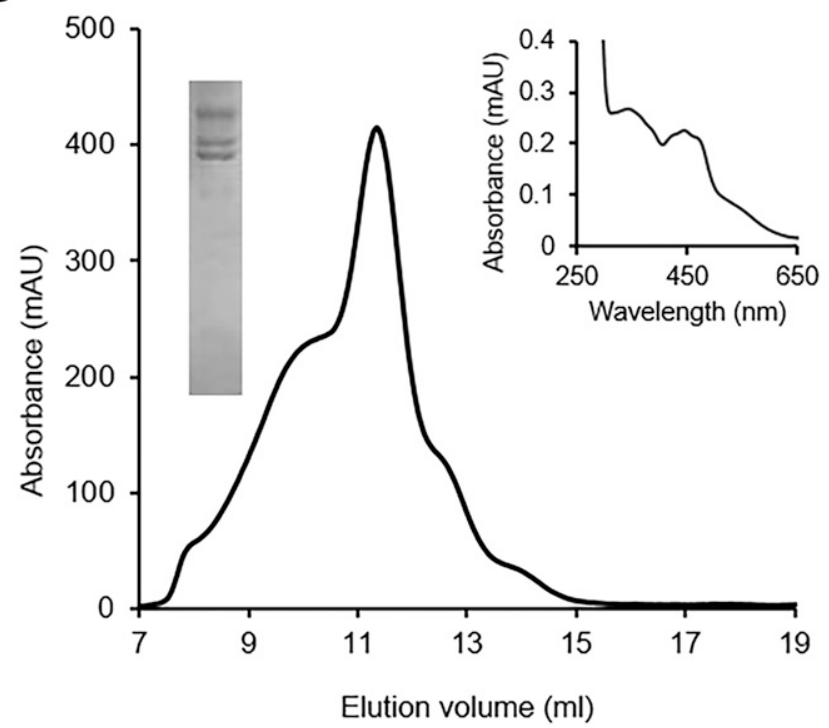

B

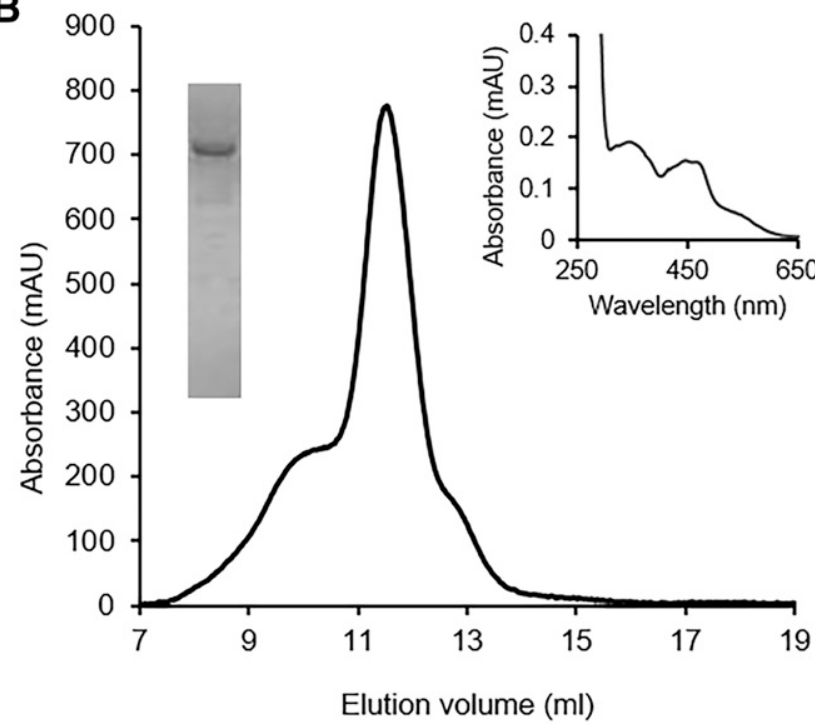

D

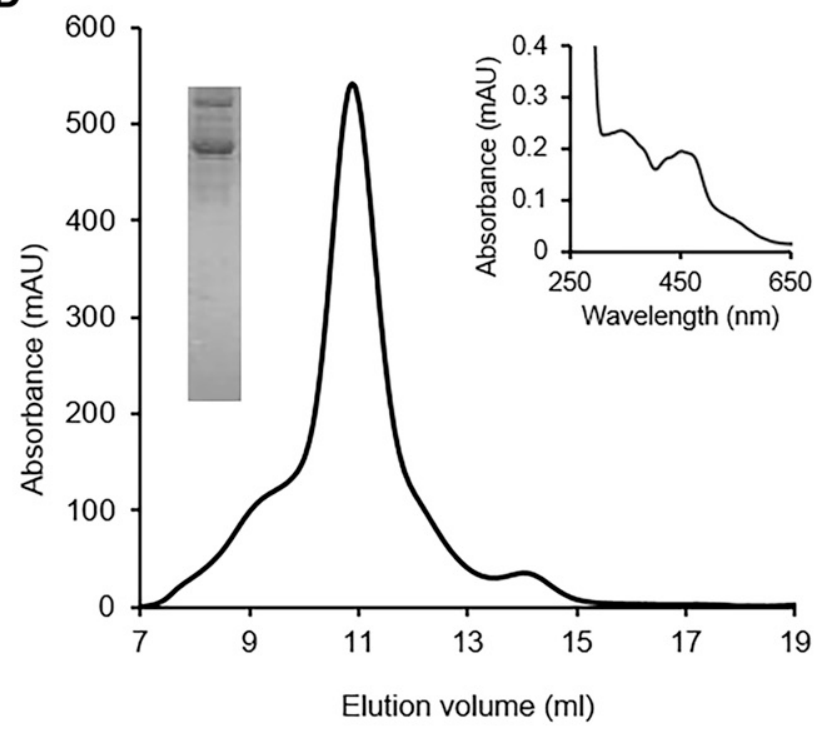

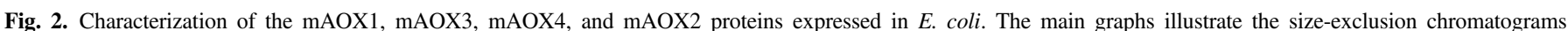

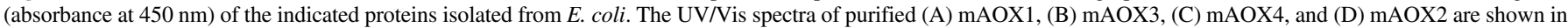

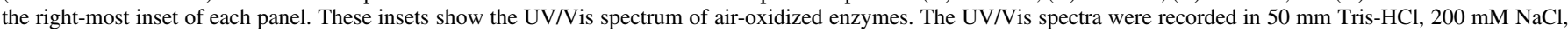

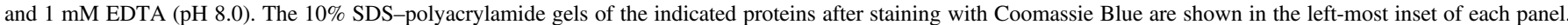

same conditions, mAOX 4 and $\mathrm{mAOX} 2$ were not fully reduced, as slower migrating bands, representing the corresponding multimeric forms, were readily detectable (Fig. 2, A-D). The bands around $130 \mathrm{kDa}, 80 \mathrm{kDa}$, and $50 \mathrm{kDa}$ identified for all enzymes (Kundu et al., 2007; Mahro et al., 2011) corresponded to degradation products, as confirmed by electrospray mass spectroscopy analysis (data not shown).

The levels of molybdenum and iron saturation for purified AOX1, AOX3, AOX4, and AOX2 were determined by inductively coupled plasma optical emission spectroscopy (Fig. 3). In the case of mAOX1, molybdenum saturation levels around $40 \%$ were calculated, and approximately $50 \%$ values were detected for $\mathrm{mAOX} 3, \mathrm{mAOX} 4$, and mAOX2. The iron saturation levels were around $60 \%$ for all the enzymes and reflected the saturation with $2 \times[2 \mathrm{Fe}-2 \mathrm{~S}]$ clusters. In conclusion, heterologous expression of the four mAOX enzymes in $E$. coli resulted in incomplete but comparable overall metal and cofactor saturation. The incomplete saturation with Moco and $[2 \mathrm{Fe}-2 \mathrm{~S}]$ clusters has been reported before for other molybdoflavoenzymes expressed in E. coli (Mahro et al., 2011; Hartmann et al., 2012; Foti et al., 2016). For the purification of AOX enzymes from native sources like mouse livers, however, cofactor saturation levels were generally not reported for comparison (Terao et al., 2001).

Direct Comparison of the Activities of the mAOX Enzymes with Selected Substrates. To compare the kinetic parameters of mAOX1, mAOX3, mAOX4, and mAOX2, the steady-state kinetics of the four enzymes were determined with pyridoxal, vanillin, 4-(dimethylamino) cinnamaldehyde ( $p$-DMAC), $N^{1}$-methylnicotinamide, salicylaldehyde, and retinaldehyde as substrates. These substrates were selected because they are of physiologic and toxicological interest and their use as substrates for rat, human, rabbit, or mouse AOX enzymes isolated from liver extracts were reported before (Stanulović and Chaykin, 1971; Stell et al., 1989; Obach, 2004; Kitamura et al., 2008; Terao et al., 2009) The kinetic parameters were determined by a spectrophotometric assay on the basis of the two-electron reduction of the electron acceptor DCPIP to 


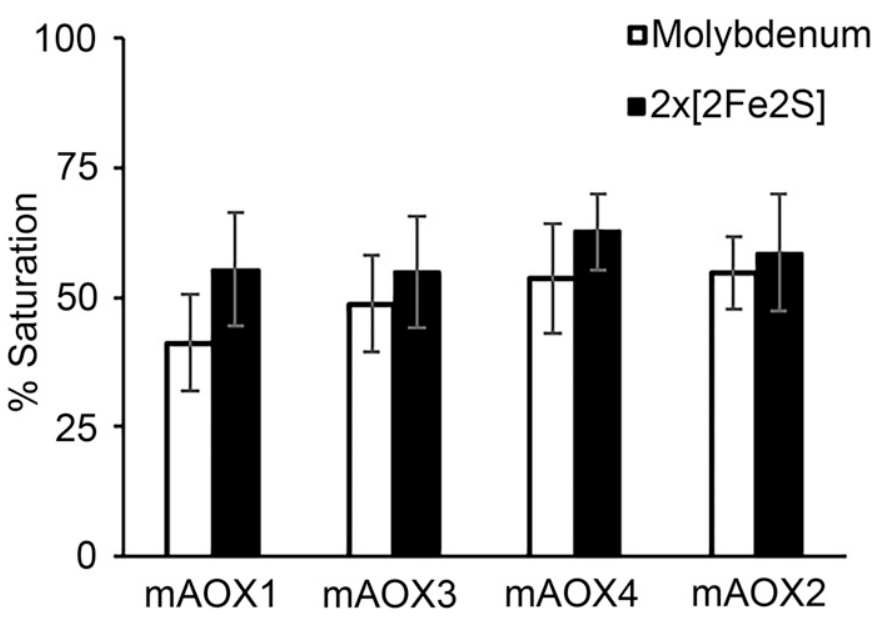

Fig. 3. Molybdenum and iron saturation of purified mAOX proteins. After purification, the molybdenum and iron content of the indicated enzymes were determined by inductively coupled plasma optical emission spectroscopy. The iron content corresponds to saturation with both, FeSI and FeSII clusters. The percentage values are calculated on the basis of the theoretical values of Moco and $2 \times[2 \mathrm{Fe}-2 \mathrm{~S}]$ clusters saturation.

$\mathrm{DCPIPH}_{2}$. The $K_{M}$ and $k_{\text {cat }}$ values calculated for each AOX enzyme and substrate are shown in Table 2 . To obtain better comparability of the data across the four AOXs, the kinetic constants were corrected and normalized for a $100 \%$ molybdenum saturation level of the purified enzymes.

As for mAOX1, the most efficient substrate is $p$-DMAC with a catalytic efficiency of $34.1 \mathrm{~min}^{-1} \mu \mathrm{M}$ (Table 2). Vanillin shows the highest $k_{\text {cat }}$ value $\left(449.9 \pm 26.4 \mathrm{~min}^{-1}\right)$, although the affinity of this substrate for the enzyme is relatively low, as indicated by the high $K_{M}$ value $(104.05 \pm 17.67 \mu \mathrm{M})$. Similar $k_{\text {cat }}$ values are evident following challenge of mAOX1 with salicylaldehyde and retinaldehyde. In spite of the consistent values for $k_{c a t}$, the catalytic efficiency calculated for mAOX1 with retinaldehyde is five times higher than with salicylaldehyde. Pyridoxal and $N^{1}$-methylnicotinamide are not efficient mAOX1 substrates, as indicated by the inability to measure detectable enzymatic activity.
In the case of $\operatorname{mAOX} 3$, the $k_{\text {cat }}$ values obtained with the various substrates considered are generally lower than the ones calculated for mAOX1. As with mAOX1, mAOX3 shows the highest catalytic efficiency when challenged with $p$-DMAC (196.73 $\left.\min ^{-1} \mu \mathrm{M}\right)$. In addition, the calculated $K_{M}$ values indicate that $\mathrm{mAOX} 3$ is characterized by a significantly higher affinity for vanillin and salicylaldehyde than mAOX1. The most remarkable difference between the two AOX enzymes is represented by the ability of AOX3 to recognize $N^{1}$-methylnicotinamide as a substrate. Finally, mAOX2 also showed the highest catalytic efficiency with $p$-DMAC as substrate with a value of $125.28 \mathrm{~min}^{-1} \mu \mathrm{M}$. Overall, the $k_{\text {cat }}$ values of mAOX2 were about half those of vanillin, $p$-DMAC, and retinaldehyde compared with mAOX3, whereas for $N^{1}$-methylnicotinamide a 2-fold higher $k_{\text {cat }}$ value was obtained in comparison with mAOX3.

Regardless of the substrate considered and with the exception of salicylaldehyde, mAOX4 is the enzyme characterized by the lowest $k_{\text {cat }}$ values. As was observed for mAOX1, $N^{1}$-methylnicotinamide is not recognized as a substrate by mAOX4. In addition, AOX4 shows the highest catalytic efficiency upon challenge with $p$-DMAC $\left(36.3 \mathrm{~min}^{-1}\right.$ $\mu \mathrm{M})$. Surprisingly and contrary to the idea that AOXs are involved in the metabolism of vitamin B6 [Kyoto Encyclopedia of Genes and Genomes (KEGG) pathways, http://www.genome.jp/kegg], pyridoxal is not recognized as a substrate by any of the four mouse AOX enzymes. To confirm this important observation, we further evaluated the ability of mAOX1, mAOX3, mAOX4, and mAOX2 to oxidize pyridoxal, using as a basis an active enzyme staining assay with native polyacrylamide gel electrophoresis under nonreducing conditions (Marelja et al., 2014). In fact, this assay allows long incubation times with the selected AOX substrate and it is characterized by an unmatched level of sensitivity under these experimental conditions. After separation, the four mAOXs migrated as single bands, confirming the purity of our preparations (Fig. 4). More importantly, no signal was observed in correspondence to the mAOX1, mAOX3, mAOX4, and mAOX2 protein bands upon overnight incubation of the gels with pyridoxal as substrate. In contrast, easily detectable bands were observed when the gels are challenged with phthalazine as a substrate even after a much shorter incubation time (Fig. 4). Taken together, these results fully confirm the observation that pyridoxal is not a substrate of any of the mAOX enzymes and reveal that

TABLE 2

Steady state kinetic parameters of $\mathrm{mAOX} 1, \mathrm{mAOX} 3, \operatorname{mAOX} 4$, and $\mathrm{mAOX} 2$

Steady-state kinetics were corrected to molybdenum saturation of $100 \%$. Kinetic parameters were recorded in $50 \mathrm{mM} \mathrm{Tris-HCl,} 200 \mathrm{mM}$ $\mathrm{NaCl}$, and $1 \mathrm{mM}$ EDTA $(\mathrm{pH} 8.0)$ in the presence of $100 \mu \mathrm{M}$ DCPIP as electron acceptor. Data are mean values from three independent measurements ( \pm S.D.).

\begin{tabular}{llcccc}
\hline \multicolumn{1}{c}{ Substrate } & \multicolumn{1}{c}{ Kinetic Parameters } & mAOX1 & mAOX3 & mAOX4 & mAOX2 \\
\hline Pyridoxal & $k_{\text {cat }}\left(\mathrm{min}^{-1}\right)$ & N.D. & N.D. & N.D. & N.D. \\
& $K_{M}(\mu \mathrm{M})$ & & & & \\
& $k_{\text {cat }} / K_{M}\left(\mathrm{~min}^{-1} \times \mu \mathrm{M}^{-1}\right)$ & & & & \\
Vanillin & $k_{\text {cat }}\left(\mathrm{min}^{-1}\right)$ & $449.9 \pm 26.4$ & $159.5 \pm 3.8$ & $15.9 \pm 2.2$ & $80.4 \pm 11.5$ \\
& $K_{M}(\mu \mathrm{M})$ & $104.0 \pm 17.7$ & $4.6 \pm 0.5$ & $5.4 \pm 0.5$ & $2.3 \pm 0.7$ \\
& $k_{\text {cat }} / K_{M}\left(\mathrm{~min}^{-1} \cdot \mu \mathrm{M}^{-1}\right)$ & 4.3 & 34.5 & 2.9 & 42.1 \\
$p$-DMAC & $k_{\text {cat }}\left(\mathrm{min}^{-1}\right)$ & $116.2 \pm 7.3$ & $88.5 \pm 4.8$ & $30.5 \pm 4.2$ & $44.8 \pm 3.7$ \\
& $K_{M}(\mu \mathrm{M})$ & $3.3 \pm 0.2$ & $0.5 \pm 0.1$ & $0.8 \pm 0.1$ & $0.4 \pm 0.1$ \\
& $k_{\text {cat }} / K_{M}\left(\mathrm{~min}^{-1} \cdot \mu \mathrm{M}^{-1}\right)$ & 34.1 & 196.7 & 36.3 & 125.3 \\
$N^{1}$-Methylnicotinamide & $k_{\text {cat }}\left(\mathrm{min}^{-1}\right)$ & $\mathrm{N} . \mathrm{D}$. & $19.6 \pm 4.8$ & $\mathrm{~N} . \mathrm{D}$. & $49.1 \pm 5.7$ \\
& $K_{M}(\mu \mathrm{M})$ & & $27.9 \pm 2.5$ & 0.7 & $9.4 \pm 3.2$ \\
Salicylaldehyde & $k_{\text {cat }} / K_{M}\left(\mathrm{~min}^{-1} \cdot \mu \mathrm{M}^{-1}\right)$ & & & 5.2 \\
& $k_{\text {cat }}\left(\mathrm{min}^{-1}\right)$ & $137.5 \pm 2.7$ & $213.0 \pm 23.4$ & $205.2 \pm 6.7$ & $221.8 \pm 49.7$ \\
& $K_{M}(\mu \mathrm{M})$ & $89.6 \pm 2.9$ & $3.5 \pm 0.1$ & $13.2 \pm 2.4$ & $21.1 \pm 12.0$ \\
Retinaldehyde & $k_{\text {cat }} / K_{M}\left(\mathrm{~min}^{-1} \cdot \mu \mathrm{M}^{-1}\right)$ & 1.5 & 60.4 & 15.6 & 10.5 \\
& $k_{\text {cat }}\left(\mathrm{min}^{-1}\right)$ & $122.7 \pm 5.1$ & $46.5 \pm 6.8$ & $10.6 \pm 1.2$ & $27.9 \pm 0.4$ \\
& $K_{M}(\mu \mathrm{M})$ & $16.5 \pm 2.4$ & $32.1 \pm 5.6$ & $12.6 \pm 2.3$ & $26.4 \pm 1.57$ \\
& $k_{\text {cat }} / K_{M}\left(\mathrm{~min}^{-1} \cdot \mu \mathrm{M}^{-1}\right)$ & 7.4 & 1.4 & 0.8 & 1.1 \\
\hline
\end{tabular}

N.D., no activity was detectable 

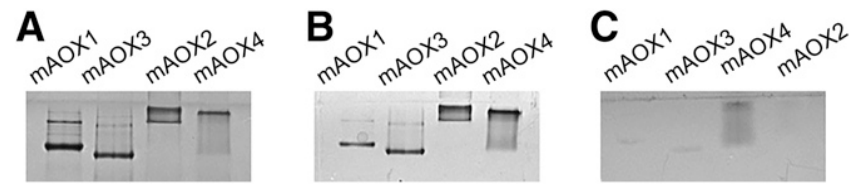

Fig. 4. Activity staining of mAOX enzymes. The figure illustrates $7 \%$ native polyacrylamide gels of purified mAOX1, mAOX3, mAOX4, and mAOX2 $(10 \mu \mathrm{g})$ run under nondenaturing conditions: Gels were stained with (A) Coomassie Brilliant Blue or $1 \mathrm{mM}$ Nitro blue tetrazolium chloride following incubation with (B) $500 \mu \mathrm{M}$ phthalazine for 5 minutes and (C) $500 \mu \mathrm{M}$ pyridoxal-5-monophosphate overnight.

the enzymes probably do not play a significant role in the catabolism of vitamin B6 (Stanulović and Chaykin, 1971; Garattini et al., 2008).

mAOX3 Is the Sole Enzyme with NADH Oxidase Activity. We investigated differences at the flavin site of the mAOX enzymes. AOX enzymes are characterized by the exclusive use of molecular oxygen as electron acceptor. In contrast, the other molybdoflavoenzyme xanthine dehydrogenase $(\mathrm{XDH})$ uses $\mathrm{NAD}^{+}$as the electron acceptor in its dehydrogenase form, as it solely transfers the reducing equivalents to molecular oxygen upon conversion into its oxidase form (XO) (Okamoto et al., 2013). Despite the inability to react with $\mathrm{NAD}^{+}, \mathrm{XO}$ can be reduced by NADH (Olson et al., 1974). The ability of XO to interact with NADH but not with $\mathrm{NAD}^{+}$is a consequence of the different
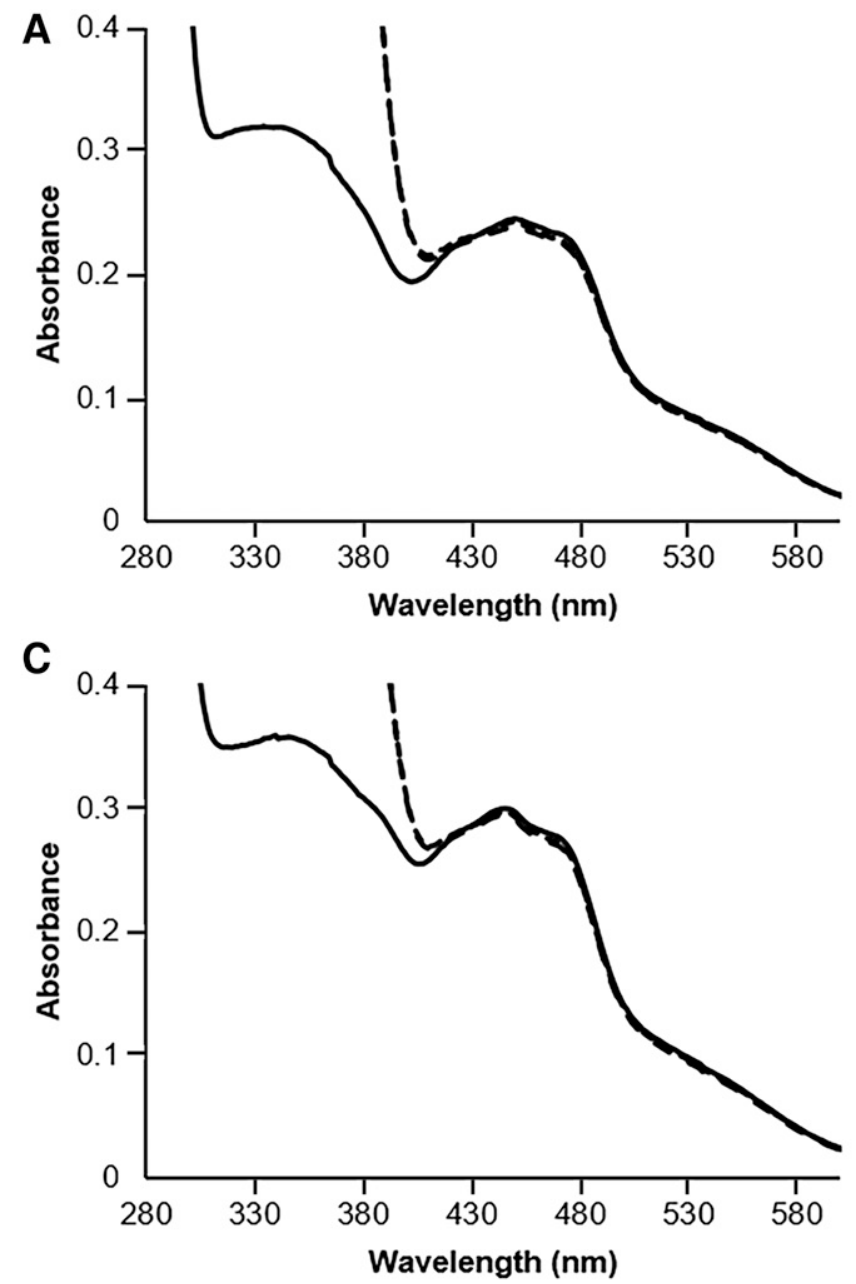

redox potentials of the FAD cofactor in the $\mathrm{XDH}$ and $\mathrm{XO}$ forms. For these reasons, we determined the relative ability of the four mAOX enzymes to oxidize NADH in the absence of oxygen (Fig. 5). Each enzyme at approximately $10 \mu \mathrm{M}$ concentration was incubated with $500 \mu \mathrm{M}$ NADH under anaerobic conditions and the corresponding absorption spectra were recorded after 1 and 20 minutes of incubation. NADH was able to reduce only mAOX3 and complete reduction was observed after 20 minutes of incubation. The result supports the data from the crystal structure showing that the environment around FAD is different in mAOX3 relative to mAOX1, mAOX4, or mAOX2 (Coelho et al., 2012).

mAOX2 Produces the Highest Rate of Superoxide Anions. The mAOX enzymes investigated here are all oxidases that use molecular oxygen as electron acceptor and do not react with $\mathrm{NAD}^{+}$. In the reduction spectra, the formation of a flavin semiquinone was also not observed (Schumann et al., 2009; Mahro et al., 2011; data not shown). AOXs have been reported to produce large amounts of $\mathrm{H}_{2} \mathrm{O}_{2}$ as the final reaction product. However, potential and enzyme-specific differences in the rate of superoxide production have never been investigated before (Kundu et al., 2007). The production of $\mathrm{O}_{2}^{-}$can be conveniently monitored by including cytochrome $c$ in the reaction mixture. In fact, cytochrome $c$ reduction by $\mathrm{O}_{2}^{-}$is considerably faster than spontaneous $\mathrm{O}_{2}^{-}$dismutation. The amount of $\mathrm{O}_{2}^{-}$produced in the reaction mixture was estimated by comparison with a blank reaction run under the same

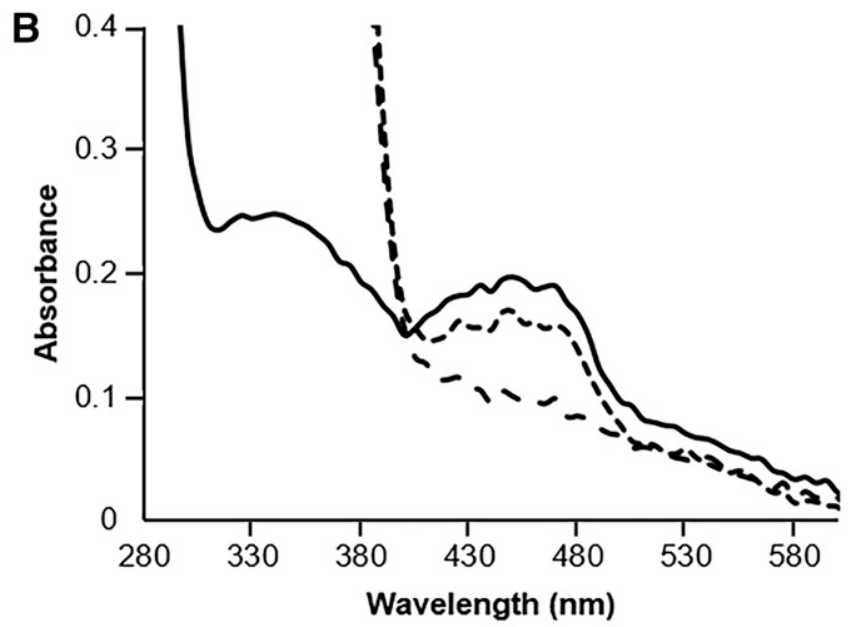

D

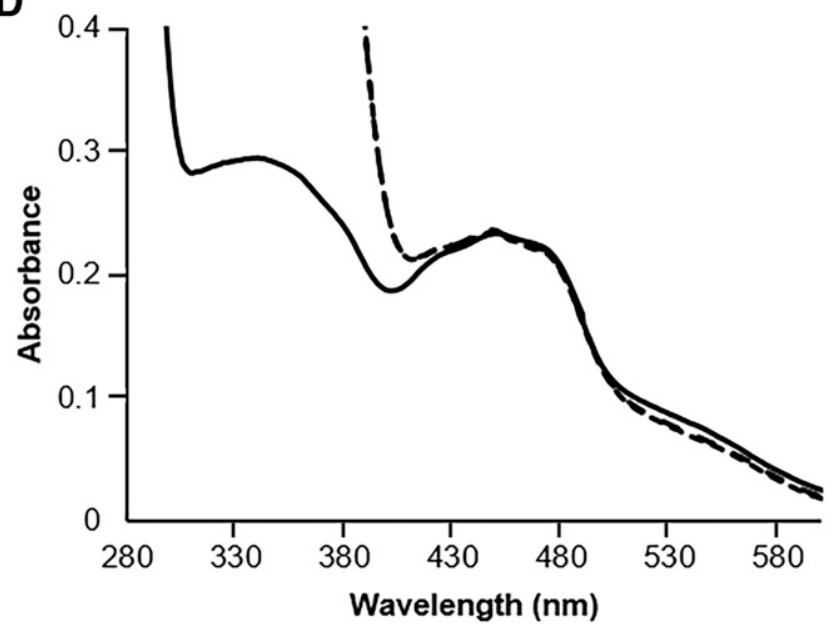

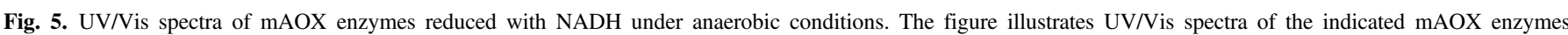

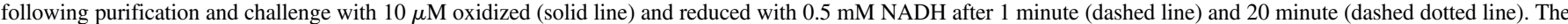
spectra were recorded in $50 \mathrm{mM}$ Tris- $\mathrm{HCl}, 200 \mathrm{mM} \mathrm{NaCl}$ and $1 \mathrm{mM}$ EDTA (pH 8.0). (A) mAOX1, (B) mAOX3, (C) mAOX4, and (D) mAOX2. 
conditions in the presence of superoxide dismutase. The experiment was performed in the presence of $50 \mu \mathrm{M}$ vanillin and $p$-DMAC as substrates to compare possible influences of the substrate on the rate of superoxide production. To obtain the percentage of $\mathrm{O}_{2}^{-}$production, the reduction of cytochrome $c$ (U/ $\mu$ mol enzyme) was related to the overall rate of substrate consumption (U/ $\mu \mathrm{mol}$ enzyme) (Table 3 ) determined by the product formation using vanillin and $p$-DMAC as substrates. The results in Table 3 show that mAOX2 is characterized by the highest rate of superoxide production per substrate turnover. Indeed, the enzyme produces approximately $40 \%$ of $\mathrm{O}_{2}^{-}$during turnover with vanillin and $p$-DMAC. In terms of $\mathrm{O}_{2}^{-}$production, $\mathrm{mAOX} 2$ is followed by $\mathrm{mAOX} 1$ with a superoxide production rate of around $30 \%$ per mole of substrate converted. The lowest percentage of these radical species is observed with mAOX3 and mAOX 4 which produce around $20 \%$ of superoxide radicals during substrate turnover. Since the same ratios of $\mathrm{O}_{2}^{-} /$substrate converted were obtained with different substrates used in the assay, the ratio seems to be independent of the substrate used.

\section{Discussion}

AOX is gaining recognition as a drug-metabolizing enzyme. However, AOX-mediated drug metabolism is not very well understood so far. Conventional methods to predict human AOX1 metabolism from preclinical animal model data are often not suitable owing to interspecies differences in AOX activity. Mice, rats, rabbits, and dogs generally used in the prediction of drug metabolism fail to accurately predict AOX metabolism because they express a different complement of AOX enzymes. For example, rodents such as mice and rat express AOX1 and AOX3 in the liver, whereas dogs express none (Garattini et al., 2009). Humans, on the other hand, express a single AOX1 enzyme (Garattini et al., 2009). To understand how to predict AOX clearances in humans, we need to understand the structural determinants of substrate specificity among the different enzymes. Human AOX 1 is $85 \%$ identical to mouse AOX1, whereas the other enzymes differ by $61-65 \%$ among each other (Garattini and Terao, 2011). Combinations of homology modeling and molecular dynamics simulations demonstrated major differences among mAOX1, mAOX $3, \operatorname{mAOX} 4$, and mAOX 2 at the protein surface and in the substrate-binding region (Cerqueira et al., 2015). In particular, specific amino acids characteristic for each enzyme in the substratebinding site were predicted to be responsible for differences in the catalytic activity and substrate and inhibitor specificities (Vila et al., 2004).

Here we report on the purification of the four mouse AOX enzymes in the heterologous expression system represented by the E. coli TP1000 strain to directly investigate differences among the different enzymes. The major aim of the study was to compare the catalytic activities of
mAOX1, mAOX3, mAOX 4, and mAOX2 directly and without crosscontaminations by the other enzymes, as might have been the case with the native enzymes purified from mouse tissues. A study directly comparing the purified enzymes has not been reported before and helps to explain differences in previous studies that used animal systems like rats, mice, or rabbits, all expressing the four enzymes (Stanulović and Chaykin, 1971; Kundu et al., 2012). We optimized and applied the same method for the purification of the four mouse AOXs. The basis of the established method is a two-step purification protocol involving Ni-NTA and size-exclusion chromatography. The procedure resulted in pure enzymes and an increased yield compared with the previous purification procedures described for recombinant mAOX1 and mAOX3 (Schumann et al., 2009; Mahro et al., 2011). The high yields of $\mathrm{mAOX} 1$ and $\mathrm{mAOX} 2$ are a consequence not only of the changes in the purification method, but also of the use of a codon-optimized expression vector and a chemical sulfuration step. The combination of these two factors gave rise to a 150-fold increase in the yield of mAOX1.

We profiled the four mouse AOX enzymes with three potential substrates of physiologic significance, i.e., retinaldehyde, $N^{1}$-methylnicotinamide, and pyridoxal, as well as three other molecules of toxicological relevance, i.e., vanillin, $p$-DMAC, and salicylaldehyde. Overall, mAOX1 showed the highest $k_{c a t}$ values for most of the substrates tested. The only exception is represented by retinaldehyde, which is a substrate recognized by the four enzymes with similar affinity. This last result substantially confirms and complements the results obtained on native mAOX1 and mAOX3, which demonstrated only minor differences in the $K_{M}$ and $k_{\text {cat }}$ of the two enzymes for retinaldehyde (Vila et al., 2004). So far, one or more unspecified mouse AOX enzymes have been deemed to be involved in nicotinamide metabolism thanks to their ability to generate pyridones (Stanulović and Chaykin, 1971). Interestingly, our data indicate that mAOX1 and mAOX4 do not recognize $N^{1}$-methylnicotinamide as a substrate. In contrast, $N^{1}$-methylnicotinamide is a 5 -fold more efficient substrate of $\mathrm{mAOX} 2$ relative to $\mathrm{mAOX} 3$. This indicates that liver $N^{1}$-methylnicotinamide metabolism observed in mouse liver cytosolic extracts results from mAOX3, the major form of hepatic AOX, and not mAOX1, which is expressed at much lower levels in this tissue (Stanulović and Chaykin, 1971; Kitamura et al., 2008). The metabolism of $N^{1}$-methylnicotinamide by human AOX1 has not been investigated with purified enzyme before. Studies on humanized mice extracts showed some discrepancies in respect to product formation compared with the products in mice; thus, we can only speculate here whether $N^{1}$-methylnicotinamide is indeed a substrate of hAOX1 (Kitamura et al., 2008). A recent computational study predicted structural differences in the substrate-binding funnel of the four mouse AOXs (Cerqueira et al., 2015). In particular, mAOX1 has been proposed to be endowed with the widest substrate-binding

TABLE 3

Superoxide production of $\operatorname{mAOX} 1, \operatorname{mAOX} 3, \operatorname{mAOX} 4$, and $\mathrm{mAOX} 2$

Superoxide production of enzymes was calculated by following the reduction of $100 \mu \mathrm{M}$ cytochrome $\mathrm{c}$ at $550 \mathrm{~nm}$ in the presence of $50 \mu \mathrm{M}$ substrate ( $p$-DMAC or vanillin) in $50 \mathrm{mM}$ Tris- $\mathrm{HCl}, 200 \mathrm{mM} \mathrm{NaCl}$, and $1 \mathrm{mM}$ EDTA (pH 8.0) buffer. Substrate consumption was monitored directly by the decrease in UV absorbance at wavelengths of 398 and $347 \mathrm{~nm}$ for p-DMAC and vanillin, respectively, in the presence of oxygen as electron acceptor. Extinction coefficients used are $21,000 \mathrm{M}^{-1} \mathrm{~cm}^{-1}$ for cytochrome c, $30,500 \mathrm{M}^{-1} \mathrm{~cm}^{-1}$ for vanillin, and $25,100 \mathrm{M}^{-1} \mathrm{~cm}^{-1}$ for $p$-DMAC.

\begin{tabular}{llcccc}
\hline Substrate & & mAOX1 & mAOX3 & mAOX4 & mAOX2 \\
\hline \multirow{3}{*}{ Vanillin } & Substrate consumption $\left(\mathrm{U} \mu \mathrm{mol}^{-1}\right.$ of enzyme) & 51.85 & 29.72 & 9.17 & 5.78 \\
& Superoxide formation $\left(\mathrm{U} \mu \mathrm{mol}^{-1}\right.$ of enzyme) & 16.45 & 6.92 & 1.88 & 2.42 \\
& Ratio (\%) & 31.7 & 23.3 & 20.4 & 41.8 \\
& Substrate consumption $\left(\mathrm{U} \mu \mathrm{mol}^{-1}\right.$ of enzyme) & 142.28 & 27.44 & 19.37 & 15.83 \\
p-DMAC & Superoxide formation $\left(\mathrm{U} \mu \mathrm{mol}^{-1}\right.$ of enzyme) & 43.47 & 5.25 & 3.84 & 6.21 \\
& Ratio (\%) & 30.6 & 19.1 & 19.9 & 39.3 \\
\hline
\end{tabular}

One unit (U) is defined as the oxidation of $1 \mu \mathrm{mol}$ substrate per minute under assay conditions. 
region, whereas $\mathrm{mAOX} 4$ has been predicted to contain the narrowest one. The experimental results obtained with $N^{1}$-methylnicotinamide are not entirely consistent with the predictions. In fact, neither mAOX1 nor mAOX4 use this substrate, whereas $N^{1}$-methylnicotinamide is a good mAOX2 and mAOX3 substrate (Mahro et al., 2013).

Pyridoxal is one of the forms of vitamin B6 and a potential physiologic substrate of human AOX1 KEGG pathways. Previous data indicated that the native form of $\operatorname{mAOX} 3$, purified from liver, was capable of oxidizing pyridoxal into pyridoxic acid, whereas the native form of mAOX4, purified from the Harderian gland, was unable to oxidize this aldehyde into the corresponding carboxylic acid (Terao et al., 2009). The results of the current study demonstrate, however, the inability of the four recombinant $\mathrm{mAOX}$ enzymes to recognize pyridoxal as a substrate. At present, we do not have any explanation for the discrepancy observed between the results obtained with native and recombinant mAOX3. However, from the results with mouse enzymes, it can be predicted only that pyridoxal is also not a substrate of the human enzyme. This needs further investigation.

We used our purified mAOX enzymes to test the reactivity of the above substrates at the FAD site. In particular, we determined NADH oxidase activity and the amount of $\mathrm{O}_{2}^{-}$radical production from molecular oxygen. $\mathrm{NADH}$ is found in all living cells and it is the major source of the electrons transported by the mitochondria and responsible for the synthesis of ATP. Hepatic AOX preparations have been shown to oxidize $\mathrm{NADH}$, thereby generating the reducing equivalents necessary for $\mathrm{O}_{2}^{-}$production from molecular oxygen (Kundu et al., 2007; Maia et al., 2007; Choughule et al., 2015). However, the basis of most of these studies is the use of hepatic cytosolic extracts obtained from rats or rabbits containing mixtures of AOX1 and AOX3. Even a study by Maia et al. (2015), which investigated nitrate reductase activity using rat liver and human liver extracts, investigated the NADH oxidase activity only with rat liver extracts and not with the human source (Maia et al., 2015). Our results indicate that $\mathrm{mAOX} 3$ is the only enzyme that can be reduced by NADH. mAOX 3 is the major AOX enzyme expressed in mouse liver; hence, it is possible that the associated NADH oxidase is capable of producing significant amounts of $\mathrm{O}_{2}^{-}$in this tissue. As mAOX1 is the human AOX1 ortholog, it is probable that hAOX1 is also incapable of reacting with $\mathrm{NADH}$. The different reactivity with $\mathrm{NADH}$ of AOX1 and AOX 3 can be explained by the crystal structure of the enzymes, where a different loop at the FAD site of hAOX1 and mAOX3 became visible. The crystal structure of hAOX1 revealed that a loop close to the FAD pocket $\left(\mathrm{T}_{1230} \mathrm{RGPDQ} \mathrm{Q}_{1235}\right)$ is flipped by almost $180^{\circ}$ relative to mouse AOX3. Thus, the NADH binding site might be blocked by this loop in AOX1 enzymes and probably also in the AOX4 and AOX2 enzymes, for which no structural data are available so far. However, studies on the reducibility of hAOX1 by NADH are missing in the literature so far. All available studies investigated rat liver or rabbit liver extracts; thus, from our data it can be concluded that the NADH oxidase activity reported in these studies is mainly derived from the activity of AOX3.

So far, mainly xanthine oxidase has been implicated in the generation of significant amounts of $\mathrm{O}_{2}^{--}$during the course of their catalytic activity against recognized substrates (Kundu et al., 2007). However, taking into account the relative levels of enzymatic activity of $\mathrm{XO}$ and $\mathrm{AOX}$ in human liver (Krenitsky et al., 1972), AOX1 has been calculated to generate 24-fold larger amounts of superoxide than XO. Thus, human AOX1 might represent a significant source of ROS in the cytosol and therefore might play a critical role in ROS-mediated tissue injury under specific conditions (Kundu et al., 2012). Given this background, we compared the production of $\mathrm{O}_{2}^{-}$by purified $\mathrm{mAOX} 1, \mathrm{mAOX} 3, \mathrm{mAOX} 4$, and $\mathrm{mAOX} 2$. Our results indicate a different rate of $\mathrm{O}_{2}^{--}$production by each mouse AOX enzyme in relation to the amount of substrate converted (in moles of $\mathrm{O}_{2}^{-}$produced per mole of substrate converted).
This ratio seems to be independent of the substrate used, since the same ratios of $\mathrm{O}_{2}^{-} /$substrate converted were obtained with different substrates used in the assay. In particular, mAOX 2 is the most efficient producer of superoxide anions with a rate of $40 \%$. As the enzyme is located in the nasal mucosa, which is one of the main sites of entrance for infective agents, it is possible to speculate that $\mathrm{mAOX} 2$ produces reactive ROS to protect mice from viral and bacterial infections. A similar role may be played by mAOX1 and/or mAOX3 in the liver. Also mAOX1 was shown to produce a ratio of $30 \%$ superoxide radicals, which is higher than the reported value of 15-20\% for XO (Hunt and Massey, 1992). Thus, hAOX1 might also be a major source of superoxide radical production in the human liver. In contrast, mAOX3 and mAOX4 produce a rate of $20 \% \mathrm{O}_{2}^{-}$radicals per mole of substrate converted, a ratio significantly lower compared with those of mAOX1 and mAOX2.

In conclusion, this study focused on the development of a simple and efficient system for the isolation and first comparative enzymatic characterization of the four mouse AOXs. The system is probably an important tool for the definition of the substrate specificity of each enzyme. At the basic level, the identification of the common and specific physiologic substrates of each enzyme will probably provide clues to the functional roles played by $\mathrm{mAOX} 1, \mathrm{mAOX} 3, \mathrm{mAOX} 4$, and $\mathrm{mAOX} 2$ in the homeostasis of the mouse. In fact, the existence of multiple and species-specific enzymatic forms of AOX is one of the most important and unresolved problems in the field. In particular, the presence of a single human AOX enzyme, i.e., AOX1, and multiple as well as tissuespecific AOXs in other animal species, with particular reference to mice and rats, has important ramifications not only for basic biology but also at the level of application. In fact, human AOX1 is of increasing interest in the context of drug metabolism and development, as the enzyme is capable of oxidizing and potentially inactivating an ever increasing number of heteroaromatic rings that are the principal components of numerous molecules of therapeutic and toxicological interest (Pryde et al., 2010). Owing to the existence of four different AOX enzymes in mice and rats but only a single AOX enzyme in humans, rodents are generally not suitable as a preclinical models for pharmacokinetic, pharmacodynamic, and toxicological studies involving drugs that are potential human AOX1 substrates (Sanoh et al., 2015). In this context, we propose that the availability of a system that allows the purification of large amounts of catalytically active human (Foti et al., 2016) and mouse AOXs could be used as the basis for screening tests aimed at establishing whether new drug candidates and available drugs represent efficient substrates for this class of enzymes. We therefore propose to directly use the purified enzymes for studies on substrate conversion, since without cross-contaminations with other enzymes, the mode of substrate conversion and inhibition can be investigated directly in molecular detail.

\section{Authorship Contributions}

Participated in research design: Kücükgöze, Terao, Garattini, Leimkühler. Conducted experiments: Kücükgöze.

Performed data analysis: Kücükgöze, Leimkühler.

Wrote or contributed to the writing of the manuscript: Kücükgöze, Terao, Garattini, Leimkühler.

\section{References}

Anantharaman V and Aravind L (2002) MOSC domains: ancient, predicted sulfur-carrier domains, present in diverse metal-sulfur cluster biosynthesis proteins including Molybdenum cofactor sulfurases. FEMS Microbiol Lett 207:55-61.

Cerqueira NM, Coelho C, Bras NF, Fernandes PA, Garattini E, Terao M, Romao MJ, and Ramos MJ (2015) Insights into the structural determinants of substrate specificity and activity in mouse aldehyde oxidases. J Biol Inorg Chem 20:209-217.

Choughule KV, Joswig-Jones CA, and Jones JP (2015) Interspecies differences in the metabolism of methotrexate: An insight into the active site differences between human and rabbit aldehyde oxidase. Biochem Pharmacol 96:288-295. 
Coelho C, Foti A, Hartmann T, Santos-Silva T, Leimkühler S, and Romão MJ (2015) Structural insights into xenobiotic and inhibitor binding to human aldehyde oxidase. Nat Chem Biol 11 779-783.

Coelho C, Mahro M, Trincão J, Carvalho AT, Ramos MJ, Terao M, Garattini E, Leimkühler S, and Romão MJ (2012) The first mammalian aldehyde oxidase crystal structure: insights into substrate specificity. J Biol Chem 287:40690-40702.

Foti A, Hartmann T, Coelho C, Santos-Silva T, Romão MJ, and Leimkühler S (2016) Optimization of the expression of human aldehyde oxidase for investigations of single-nucleotide polymorphisms. Drug Metab Dispos 44:1277-1285.

Garattini E, Fratelli M, and Terao M (2008) Mammalian aldehyde oxidases: genetics, evolution and biochemistry. Cell Mol Life Sci 65:1019-1048.

Garattini E, Fratelli M, and Terao M (2009) The mammalian aldehyde oxidase gene family. Hum Genomics 4:119-130.

Garattini E, Mendel R, Romão MJ, Wright R, and Terao M (2003) Mammalian molybdoflavoenzymes, an expanding family of proteins: structure, genetics, regulation, function and pathophysiology. Biochem J 372:15-32.

Garattini E and Terao M (2011) Increasing recognition of the importance of aldehyde oxidase in drug development and discovery. Drug Metab Rev 43:374-386.

Garattini E and Terao M (2012) The role of aldehyde oxidase in drug metabolism. Expert Opin Drug Metab Toxicol 8:487-503.

Hartmann T, Terao M, Garattini E, Teutloff C, Alfaro JF, Jones JP, and Leimkühler S (2012) The impact of single nucleotide polymorphisms on human aldehyde oxidase. Drug Metab Dispos 40: 856-864.

Hunt J and Massey V (1992) Purification and properties of milk xanthine dehydrogenase. J Biol Chem 267:21479-21485

Kitamura S, Nitta K, Tayama Y, Tanoue C, Sugihara K, Inoue T, Horie T, and Ohta S (2008) Aldehyde oxidase-catalyzed metabolism of N1-methylnicotinamide in vivo and in vitro in chimeric mice with humanized liver. Drug Metab Dispos 36:1202-1205.

Kitamura S and Sugihara K (2014) Current status of prediction of drug disposition and toxicity in humans using chimeric mice with humanized liver. Xenobiotica 44:123-134.

Krenitsky TA, Neil SM, Elion GB, and Hitchings GH (1972) A comparison of the specificities of xanthine oxidase and aldehyde oxidase. Arch Biochem Biophys 150:585-599.

Kundu TK, Hille R, Velayutham M, and Zweier JL (2007) Characterization of superoxide production from aldehyde oxidase: an important source of oxidants in biological tissues. Arch Biochem Biophys 460:113-121.

Kundu TK, Velayutham M, and Zweier JL (2012) Aldehyde oxidase functions as a superoxide generating NADH oxidase: an important redox regulated pathway of cellular oxygen radical formation. Biochemistry 51:2930-2939.

Laemmli UK (1970) Cleavage of structural proteins during the assembly of the head of bacteriophage T4. Nature 227:680-685.

Mahro M, Brás NF, Cerqueira NM, Teutloff C, Coelho C, Romão MJ, and Leimkühler S (2013) Identification of crucial amino acids in mouse aldehyde oxidase 3 that determine substrate specificity. PLoS One 8:e82285.

Mahro M, Coelho C, Trincão J, Rodrigues D, Terao M, Garattini E, Saggu M, Lendzian F, Hildebrandt P, Romão MJ, et al. (2011) Characterization and crystallization of mouse aldehyde oxidase 3: from mouse liver to Escherichia coli heterologous protein expression. Drug Metab Dispos 39:1939-1945.

Maia L, Duarte RO, Ponces-Freire A, Moura JJ, and Mira L (2007) NADH oxidase activity of rat and human liver xanthine oxidoreductase: potential role in superoxide production. $J$ Biol Inorg Chem 12:777-787

Maia LB, Pereira V, Mira L, and Moura JJ (2015) Nitrite reductase activity of rat and human xanthine oxidase, xanthine dehydrogenase, and aldehyde oxidase: evaluation of their contribution to NO formation in vivo. Biochemistry 54:685-710.
Marelja Z, Dambowsky M, Bolis M, Georgiou ML, Garattini E, Missirlis F, and Leimkühler S (2014) The four aldehyde oxidases of Drosophila melanogaster have different gene expression patterns and enzyme substrate specificities. J Exp Biol 217:2201-2211.

Mendel RR and Leimkühler S (2015) The biosynthesis of the molybdenum cofactors. J Biol Inorg Chem 20:337-347.

Obach RS (2004) Potent inhibition of human liver aldehyde oxidase by raloxifene. Drug Metab Dispos 32:89-97.

Okamoto K, Kusano T, and Nishino T (2013) Chemical nature and reaction mechanisms of the molybdenum cofactor of xanthine oxidoreductase. Curr Pharm Des 19:2606-2614.

Olson JS, Ballou DP, Palmer G, and Massey V (1974) The mechanism of action of xanthine oxidase. J Biol Chem 249:4363-4382.

Palmer T, Santini C-L, Iobbi-Nivol C, Eaves DJ, Boxer DH, and Giordano G (1996) Involvement of the narJ and mob gene products in distinct steps in the biosynthesis of the molybdoenzyme nitrate reductase in Escherichia coli. Mol Microbiol 20:875-884.

Pryde DC, Dalvie D, Hu Q, Jones P, Obach RS, and Tran T-D (2010) Aldehyde oxidase: an enzyme of emerging importance in drug discovery. J Med Chem 53:8441-8460.

Sanoh S, Tayama Y, Sugihara K, Kitamura S, and Ohta S (2015) Significance of aldehyde oxidase during drug development: Effects on drug metabolism, pharmacokinetics, toxicity, and efficacy. Drug Metab Pharmacokinet 30:52-63.

Schumann S, Terao M, Garattini E, Saggu M, Lendzian F, Hildebrandt P, and Leimkühler S (2009) Site directed mutagenesis of amino acid residues at the active site of mouse aldehyde oxidase AOX1. PLoS One 4:e5348

Stanulović M and Chaykin S (1971) Aldehyde oxidase: catalysis of the oxidation of N 1 -methylnicotinamide and pyridoxal. Arch Biochem Biophys 145:27-34.

Stell JGP, Warne AJ, and Lee-Woolley C (1989) Purification of rabbit liver aldehyde oxidase by affinity chromatography on benzamidine sepharose 6B. J Chromatogr A 475:363-372.

Terao M, Kurosaki M, Barzago MM, Fratelli M, Bagnati R, Bastone A, Giudice C, Scanziani E, Mancuso A, Tiveron C, et al. (2009) Role of the molybdoflavoenzyme aldehyde oxidase homolog 2 in the biosynthesis of retinoic acid: generation and characterization of a knockout mouse. Mol Cell Biol 29:357-377.

Terao M, Kurosaki M, Marini M, Vanoni MA, Saltini G, Bonetto V, Bastone A, Federico C, Saccone S, Fanelli R, et al. (2001) Purification of the aldehyde oxidase homolog 1 (AOH1) protein and cloning of the $\mathrm{AOH} 1$ and aldehyde oxidase homolog 2 ( $\mathrm{AOH} 2)$ genes. Identification of a novel molybdo-flavoprotein gene cluster on mouse chromosome 1. J Biol Chem 276: 46347-46363.

Terao M, Kurosaki M, Saltini G, Demontis S, Marini M, Salmona M, and Garattini E (2000) Cloning of the cDNAs coding for two novel molybdo-flavoproteins showing high similarity with aldehyde oxidase and xanthine oxidoreductase. J Biol Chem 275:30690-30700.

Terao M, Romão MJ, Leimkühler S, Bolis M, Fratelli M, Coelho C, Santos-Silva T, and Garattini E (2016) Structure and function of mammalian aldehyde oxidases. Arch Toxicol 90:753-780.

Vila R, Kurosaki M, Barzago MM, Kolek M, Bastone A, Colombo L, Salmona M, Terao M, and Garattini E (2004) Regulation and biochemistry of mouse molybdo-flavoenzymes. The $\mathrm{DBA} / 2$ mouse is selectively deficient in the expression of aldehyde oxidase homologues 1 and 2 and represents a unique source for the purification and characterization of aldehyde oxidase. $J$ Biol Chem 279:8668-8683.

Wahl RC and Rajagopalan KV (1982) Evidence for the inorganic nature of the cyanolyzable sulfur of molybdenum hydroxylases. J Biol Chem 257:1354-1359.

Address correspondence to: Dr. Silke Leimkühler, Institut für Biochemie and Biologie, Universität Potsdam, Karl-Liebknecht Str. 24-25, 14476 Potsdam, Germany. E-mail: sleim@uni-potsdam.de 